\title{
Autonomy Support, Basic Psychological Needs and Well-Being in Mexican Athletes
}

\author{
Jeanette López-Walle ${ }^{1}$, Isabel Balaguer ${ }^{2}$, Isabel Castillo², and José Tristán ${ }^{1}$ \\ ${ }^{1}$ Universidad Autónoma de Nuevo León (Mexico) \\ ${ }^{2}$ Universitat de València (Spain)
}

Based on Basic Needs Theory, one of the mini-theories of Self-determination Theory (Ryan \& Deci, 2002), the present study had two objectives: (a) to test a model in the Mexican sport context based on the following sequence: perceived coach autonomy support, basic psychological needs satisfaction, and psychological well-being, and b) to analyze the mediational effect of the satisfaction of perceived coach autonomy support on indicators of psychological well-being (satisfaction with life and subjective vitality). Six hundred and sixty-nine young Mexican athletes (Boys $=339 ;$ Girls $=330 ; M_{\text {age }}=13.95$ ) filled out a questionnaire assessing the study variables. Structural equations analyses revealed that perceived coach autonomy support predicted satisfaction of the basic psychological needs for autonomy, competence, and relatedness. Furthermore, basic need satisfaction predicted subjective vitality and satisfaction with life. Autonomy, competence and relatedness partially mediated the path from perceived coach autonomy support to psychological well-being in young Mexican athletes.

Keywords: autonomy support, psychological needs satisfaction, well-being, Basic Needs Theory, Mexican athletes.

Basado en la Teoría de las Necesidades Básicas, una de las mini-teorías de la Teoría de la AutoDeterminación (Ryan \& Deci, 2002), dos fueron los objetivos del presente estudio: (a) poner a prueba, en el contexto deportivo mexicano, un modelo basado en la secuencia: percepción del apoyo a la autonomía ofrecido por el entrenador, satisfacción de las necesidades psicológicas básicas y bienestar psicológico, y (b) analizar la mediación de la satisfacción de las necesidades psicológicas básicas entre la percepción de apoyo a la autonomía y los indicadores de bienestar psicológico (satisfacción con la vida y vitalidad subjetiva). Seiscientos sesenta y nueve jóvenes deportistas mexicanos (Chicos = 339, Chicas = 330, $M_{\text {edad }}=13.95$ ) completaron un cuestionario que evaluaba las variables del estudio. Los análisis de ecuaciones estructurales revelaron que la percepción de apoyo a la autonomía ofrecido por el entrenador predecía la satisfacción de las necesidades psicológicas básicas de autonomía, competencia y relación. A su vez, la satisfacción de las tres necesidades actuó como predictora de la vitalidad subjetiva y de la satisfacción con la vida. Los análisis de la mediación informaron que la autonomía, la competencia y la relación mediaron parcialmente la relación entre la percepción de apoyo a la autonomía ofrecido por el entrenador y el bienestar psicológico de los jóvenes deportistas mexicanos.

Palabras clave: apoyo a la autonomía, satisfacción de las necesidades psicológicas, bienestar, Teoría de las Necesidades Básicas, deportistas Mexicanos.

This work was partially funded by the Consejo Nacional de Ciencia y Tecnología (CONACYT-81333 and 103983) and the Programa Integral de Fortalecimiento Institucional (PIFI v.2009).

Correspondence concerning this article should be addressed to Jeanette López-Walle. Facultad de Organización Deportiva. Universidad Autónoma de Nuevo León. Avda. Universidad s/n Cd. Universitaria, San Nicolás de los Garza, 66051, Nuevo León (Mexico). Phone: +52-813675384. Email: jmlopezw@yahoo.com.mx 
Basic Needs Theory (BNT; Ryan \& Deci, 2002), a theory of motivation that is contributing to our understanding of how well-being and ill-being develop in social contexts, is the framework of this paper. BNT, one of the mini-theories of Self Determination Theory (SDT; Deci \& Ryan, 1985, 2000) proposes there are three basic psychological needs: competence (an individual's need to feel a sense of mastery through effective interaction with their environment), autonomy (feeling like the origin of one's actions and decisions, and having a sense of volition) and relatedness (feeling connected to and respected by others and experiencing the feeling of belonging to a group). It asserts that when basic psychological needs are satisfied, well-being is favored in everyday life, whereas when needs are thwarted, ill-being is induced (Ryan \& Deci, 2000, 2002; Deci \& Ryan, 2000). This theory proposes that developing wellbeing or ill-being depends on the social environment and its potential to satisfy the basic psychological needs.

From the perspective of eudaimonic well-being, the view supported by SDT (and BNT more specifically), subjects are active and enterprising, and interested in developing their competence and potential. From this perspective, well-being equates to growth and optimal development (Ryan \& Deci, 2001).

According to SDT, the indicator par excellence to assess eudaimonic well-being is subjective vitality, defined as one's conscious experience of possessing energy and aliveness (Ryan \& Frederick, 1997). Another variable used to evaluate subjective well-being is satisfaction with life, conceived as a cognitive-judgmental process where one completes a global, subjective evaluation of his or her life (Pavot, Diener, Colvin, \& Sandvik, 1991).

In accordance with SDT, one dimension of social contexts that facilitates the development of well-being in participants is autonomy support from authority figures. Autonomy support is the desire and will of a person in a position of authority (for example, a coach) to put him or herself in the place of others or imagine their perspective (for example an athlete or team), to determine their needs and feelings, and to offer them both appropriate and meaningful information to carry out their tasks, such as opportunities for choice (Ryan \& Deci, 2000). In that sense, in the sport context, the coach can be considered an authority figure to the athletes on the team, and will therefore play an important role in satisfying their needs for competence, autonomy and relatedness (Ryan \& Deci, 2007). Specifically, contexts where participants receive autonomy support favor the satisfaction of those needs, while in contexts where autonomy support is not provided, needs are thwarted (Ryan \& Deci, 2000).

BNT proposed that basic psychological needs, in addition to being influenced by social context and predicting wellbeing, also mediate the link between social factors (e.g. coach-created atmosphere) and psychological well-being (e.g. subjective vitality and satisfaction with life) (Ryan \& Deci, 2000).
Various studies conducted in the sport context have analyzed the relation between perceived coach autonomy support and basic psychological need satisfaction (e.g. Adie, Duda, \& Ntoumanis, 2008; Álvarez, Balaguer, Castillo, \& Duda, 2009; Balaguer, Castillo, \& Duda, 2008; Gagné, Ryan, \& Bargmann, 2003; Reinboth, Duda, \& Ntoumanis, 2004). In a study of British adult athletes of both genders, Adie and his colleagues (2008) observed a positive link between perceived coach autonomy support and satisfaction of the three basic psychological needs. The strongest relationship occurred with satisfaction of the need for relatedness, and the weakest with satisfaction of the need for competence. Similarly, in their study of Spanish, young, male soccer players, Álvarez and her colleagues (2009) found that perceived coach autonomy support was associated with satisfaction of the basic psychological needs, using the average of the three needs. By the same token, in a sample of Spanish competitive athletes of both genders and from a variety of sports, Balaguer and her colleagues (2008) reported high, positive correlations between perceived coach autonomy support and satisfaction of the basic needs for autonomy and relatedness, the first correlation being somewhat higher. Moreover, in a sample of North American gymnasts, Gagné and her colleagues (2003) showed that gymnasts' perception of their instructor's autonomy support was positively related to autonomy and relatedness need satisfaction. Finally, in a sample of British soccer and cricket players, Reinboth and his colleagues (2004) reported a positive correlation between perceived coach autonomy support and the satisfaction of the three basic psychological needs. Those researchers reported the strongest correlation with the need for autonomy and the weakest with the need for competence.

SDT postulates a positive link between the satisfaction of the basic psychological needs and psychological wellbeing, which has been studied by several authors in the sport domain using the same two indicators of well-being we considered in the present study: subjective vitality (e.g. Adie et al., 2008; Balaguer \& Castillo, 2007; Reinboth et al., 2004; Reinboth \& Duda, 2006; Edmunds, Ntoumanis, \& Duda, 2007) and satisfaction with life (e.g. Balaguer \& Castillo, 2007). First, Reinboth and his colleagues (2004) found that satisfying the needs for autonomy and competence predicted well-being as measured by the indicator of subjective vitality. Meanwhile, in a longitudinal study of British university students, Reinboth and Duda (2006) reported that satisfaction of the need for both autonomy and relatedness predicted increases in subjective vitality. In that study, however, satisfaction of the need for competence was not a predictor for this indicator of well-being. In another study, Adie and his colleagues (2008) found that satisfaction of participants' basic needs for autonomy, competence and relatedness predicted greater subjective vitality; of the three, the weakest predictor was satisfaction of the need for relatedness. Lastly, employing a sample of young, elite, Spanish, female tennis players, Balaguer and Castillo (2007) 


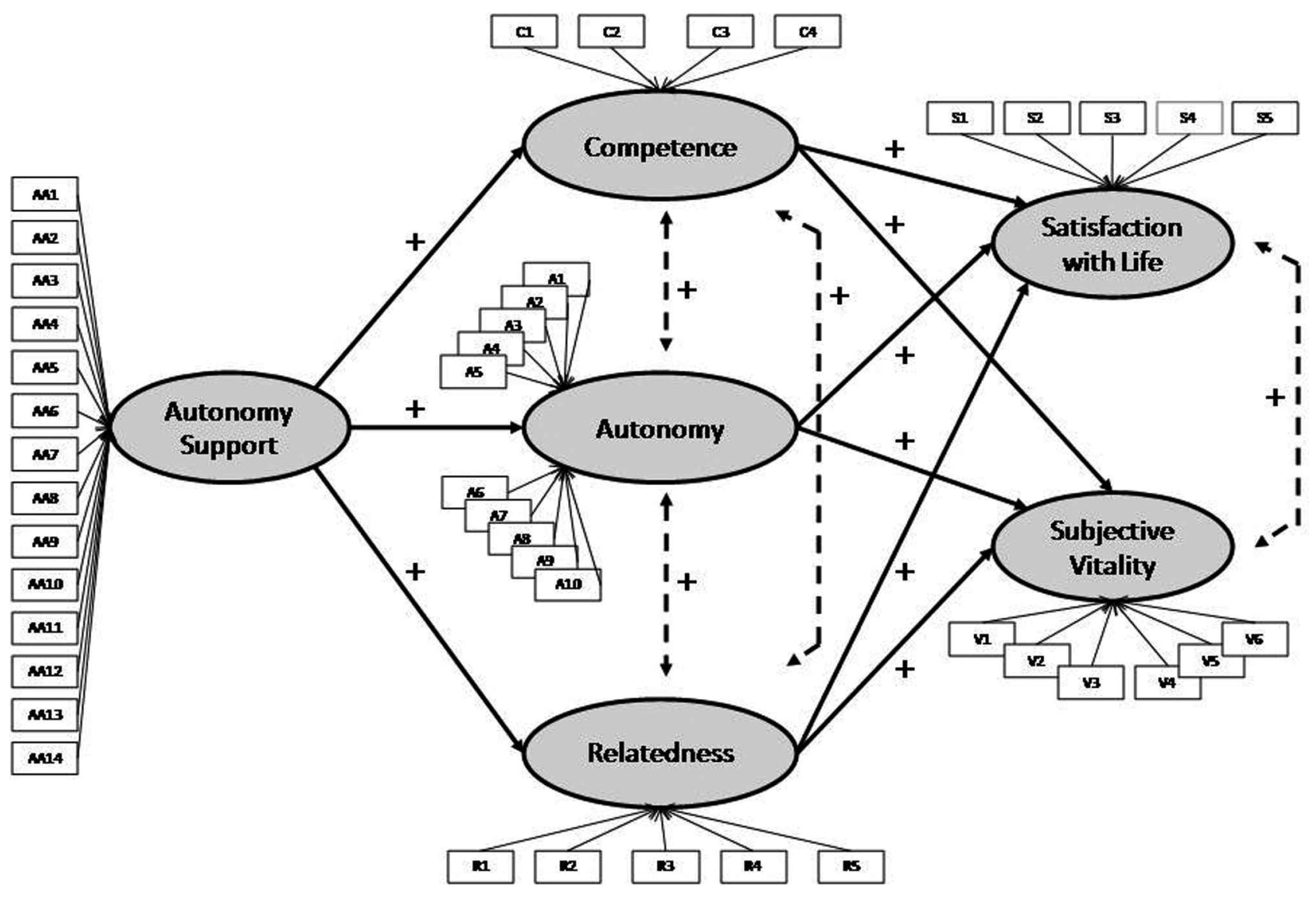

Figure 1. Hypothesized Structural Model of Antecedents and Outcomes of Basic Psychological Needs.

reported that basic psychological needs satisfaction, using the average of the three needs, predicted subjective vitality, satisfaction with life and self-esteem.

Finally, some studies in the sport domain have documented that the three psychological needs mediate the link between coach autonomy support and well-being (e.g. Adie et al., 2008; Balaguer \& Castillo, 2007). Adie and his colleagues (2008) ascertained that satisfaction of the needs for autonomy and competence partially mediated the relationship between perceived coach autonomy support and subjective vitality. Balaguer and Castillo (2007) tested the mediation of the three basic psychological needs (average), obtaining a total mediation in the relationship between social context (autonomy support) and three indicators of well-being (subjective vitality, satisfaction with life and self-esteem).

SDT's theoretical postulates are being examined by a network of researchers from different countries (see SDT's web site: http://www.psych.rochester.edu/ SDT/), which demonstrates their international impact. In relation to the present study, Deci and Ryan (2000) defend the notion that despite high variability in values and goals across different cultures, BNT is applicable in all contexts, and to all age groups and genders. Those authors suggest that while there are different ways to satisfy basic psychological needs in every culture, and their relative importance may vary, the process by which basic psychological need satisfaction promotes well-being is believed not to vary (Ryan \& Deci, 2002). As we mentioned above, SDT has been employed in Spanish studies (e.g. Álvarez et al., 2009; Balaguer et al., 2008; Balaguer \& Castillo, 2007). While the same language is spoken in Spain and Mexico, there are small variations in how the language and colloquialisms have evolved, and the two have different idiosyncratic characteristics (Fierro \& Moreno, 2007). For example, López-Walle and her colleagues (López-Walle, Tomás, Castillo, Balaguer, \& Tristán, 2011) found that in the sport domain, the normative motivational orientation (ego orientation) is more widely exhibited in Mexican athletes than in Spanish ones. In light of the above, conducting cross-cultural studies between language-sharing countries could contribute to generalizing and evolving the body of theory, as well as our basic understanding of a given field (Duda \& Hayashi, 1998), for example, sport. Until now, no study on Mexican athletes has analyzed BNT's sequence - perceived autonomy support, basic psychological need satisfaction and psychological well-being - so we believe this study will contribute an empirical test of BNT in the sport context within Mexican culture.

The principal purpose of this study was to test a model (see Figure 1) using a sample of Mexican athletes. We hypothesized that: 1) Perceptions of autonomy support 
would positively predict satisfaction of the needs for autonomy, competence and relatedness; 2) Satisfaction of the three psychological needs would positively predict both satisfaction with life and subjective vitality. The second objective was to test the mediational effects of the three psychological needs on the path from perceived coach autonomy support to the indicators of athletes' well-being (satisfaction with life and subjective vitality).

\section{Method}

\section{Participants}

The sample was comprised of 669 Mexican athletes participating in the 2008 National Child and Youth Olympiad; of them, 330 were girls and 339 boys, ranging in age from 11 to 18 years-old $(M=13.95 ; S D=1.93)$. The athletes came from 18 different sports, trained more than three days a week $(M=3.9 ; S D=1.2)$ for over two hours a day $(M=2.9 ; S D=.9)$, and had competed with the same coach for an average of 2.5 years $(S D=1.4)$.

\section{Instruments}

\section{Perceived Autonomy Support}

Perceived coach autonomy support was evaluated by means of the Spanish version (Balaguer, Castillo, Duda, \& Tomás, 2009) of the Sport Climate Questionnaire (SDTWeb site: http:www.psych.rochester.edu/SDT/). The long form of this instrument is made up of 15 items assessing the extent to which athletes perceive their coaches as supporting their autonomy. Each item begins with the phrase: "In my sport..." and responses are given on a sevenpoint Likert-type scale, ranging from not at all true (1) to very true (7). Here is a sample item: "My coach listens to how I would like to do things." Prior research has confirmed this instrument's reliability (Balaguer et al., 2009; Williams, Grow, Freedman, Ryan, \& Deci, 1996).

\section{Basic Psychological Needs}

Perceived competence was measured using the Perceived Competence Scale from the Spanish version (Balaguer et al., 2008) of the Intrinsic Motivation Inventory (McAuley, Duncan, \& Tammen, 1989). The questionnaire is comprised of five items assessing perceived competence in the sport setting. Athletes were asked to indicate their level of agreement with a series of statements such as "I am pretty skilled at my sport." Responses are given in a seven-point Likert-type format, and range from strongly disagree (1) to strongly agree (7). Prior studies have confirmed this scale's reliability (Balaguer et al., 2008; McAuley et al., 1989).
Perceived autonomy was evaluated by means of the Spanish version (Balaguer et al., 2008) of the Perceived Autonomy in Sport Scale, created by Reinboth and Duda (2006). It includes 10 items evaluating two facets of perceived autonomy: choice/decision-making and volition in the sport context. Athletes were asked to indicate how they generally feel while participating in their sports; for example: In my sport, "I feel free to do things my own way." Responses are provided on a seven-point Likert-type scale, ranging from not at all true (1) to very true (7). The scale's reliability has been confirmed by previous studies (Balaguer et al., 2008; Reinboth \& Duda, 2006).

Perceived relatedness was measured through the Spanish version (Balaguer et al., 2008) of the "Acceptance" subscale of the Need for Relatedness Scale by Richer and Vallerand (1998), which is comprised of five items assessing one's level of perceived acceptance and respect in the sport domain. Athletes are asked to indicate their personal level of agreement with statements about how they feel while practicing their sport; for example: When participating in my sport, I feel... "valued." They respond on a five-point Likert-type scale with options ranging from strongly disagree (1) to strongly agree (5). Prior research has demonstrated this instrument's reliability and validity (Balaguer et al., 2008; Richer \& Vallerand, 1998).

\section{Psychological Well-being}

Satisfaction with life was evaluated by means of the Spanish language version (Atienza, Pons, Balaguer, \& GarcíaMerita, 2000) of the Satisfaction With Life Scale (Diener, Emmons, Larsen, \& Griffin, 1985), which measures life satisfaction as a process of cognitive judgment. It is made up of five items with which athletes are asked to indicate their level of agreement on a seven-point Likert-type scale ranging from strongly disagree (1) to strongly agree (7). One sample item is "The conditions of my life are excellent." This instrument's reliability and validity have been confirmed by previous studies (Atienza et al., 2000; Diener et al., 1985).

Subjective vitality was assessed through a Spanish language version (Balaguer, Castillo, García-Merita, \& Mars, 2005) of the Subjective Vitality Scale (Ryan \& Frederick, 1997), which includes six items measuring subjective feelings of energy and liveliness. In the instructions, athletes are asked to indicate the extent to which a series of statements are true for them, in general. A sample item is "I feel alive and vital." Answers are given on a seven-point Likert-type scale ranging from not at all true (1) to very true (7). Previous research studies have attested to this instrument's reliability and validity (Balaguer et al., 2005; Ryan \& Frederick, 1997).

\section{Procedure}

Given that variations within the Spanish language can come to threaten the validity of adapted tests (Muñiz, 1996), 
we went on to revise and adapt the Spanish versions of each instrument to the Mexican context.

The six instruments' existing Spanish versions were assessed by a group of sport psychology experts at the Universidad Autónoma de Nuevo León in Mexico so as to identify any possible words or response options not appropriate to a Mexican context. Cronbach's alpha (Cronbach, 1951) was calculated for all questionnaires. To analyze each instrument's factorial structure, we employed the same procedure utilized by the authors of the original and Spanish versions (principal components, varimax rotation), so as to compare our results with the originals. We considered it appropriate to only explore factor composition (Pérez-Gil, Moscoso, \& Rodríguez, 2000).

Once we had obtained Mexican versions of each instrument, we sought permission from the parties responsible for each sport participating in the event (The National Child and Youth Olympiad, Monterrey 2010). Instruments were administered either individually or as a group, depending on the situation. It was decided that the tests be administered in hotels where the athletes were staying, assuming that would be the best context in which to distance them from potentially distracting stimuli. The athletes participated voluntarily and anonymously, taking an average of 25 minutes to fill out the six measurement instruments.

\section{Results}

\section{Analyses of Instruments}

Exploratory and confirmatory factor analyses were performed to examine the factorial structure and reliability of the Mexican versions of the instruments utilized in this study. Item 13 on the Sport Climate Questionnaire, "I don't feel very good about the way my coach talks to me," was eliminated due to its very low discrimination index $(D I=$ .14). Furthermore, its elimination improved reliability from $(\alpha=.89)$ to $(\alpha=.91)$. The total percentage of explained variance was $55.38 \%$. The Mexican version of this instrument consists of 14 items.

Meanwhile, item 5 on the Perceived Competence Scale, "I can't do (perform, play) my sport very well," was eliminated because its discrimination index was very low $(\mathrm{DI}=.01)$. In addition, eliminating that item increased reliability considerably from $(\alpha=.62)$ to $(\alpha=.81)$. The four items, with their single-factor structure, together explained $64.84 \%$ of variance. The Mexican version of this instrument consists of 4 items.

Regarding the Perceived Autonomy in Sport scale, an $(\alpha=.90)$ was obtained. All ten of the instrument's items were retained and jointly explained $51.42 \%$ of variance.

The Acceptance sub-scale of the Need for Relatedness Scale, on the other hand, yielded an alpha of .87. Also, the instrument's five items were retained, together explaining $65.34 \%$ of variance.

Next, item 5 of the Satisfaction With Life Scale was modified per the experts' suggestion, such that the item on the Spanish version, "If I could live my life over, I would change almost nothing," was replaced with "If I could live my life again, I would change nothing." A value of $(\alpha=$ .78) was observed, all five items were retained, and they together explained $54.01 \%$ of variance.

Concerning the Subjective Vitality scale, the six items on the Spanish version were retained, yielding a reliability of $(\alpha=.87)$. We confirmed the single-factor structure of both the original version and the Spanish adaptation and the items were found to explain $60.70 \%$ of variance.

Following the recommendations of $\mathrm{Hu}$ and Bentler (1999), in carrying out confirmatory factor analyses of the study's instruments, different indices were used to measure models' goodness of fit: the $\chi^{2}$ statistic divided by degrees of freedom, the comparative fit index (CFI), the non-normed fit index (NNFI), and the root mean square error of approximation (RMSEA). A $\chi^{2} / d f$ quotient below 5 represents a model with good fit to the data. Meanwhile, values of CFI and NNFI above 90 indicate acceptable fit (Hu \& Bentler, 1995). As for RMSEA, values under .05 are considered indicative of good fit, and values around .08 signify a reasonable error of approximation to the population (Browne \& Cudeck, 1993). The different structural models' results reveal that all the scales or components of the model exhibit satisfactory fit indices (Table 1), as well as adequate factor saturation (for the sake of brevity, the results of the confirmatory factor analyses are not presented here; however, they are available upon

Table 1

Goodness of Fit Indices for the Study's Instruments

\begin{tabular}{lccccc}
\hline Latent Factors & $\chi^{2}$ & $d f$ & RMSEA & NNFI & CFI \\
\hline Autonomy Support & 448.44 & 77 & .08 & .91 & .91 \\
Need for Competence & 1.11 & 2 & .00 & .00 & .00 \\
Need for Autonomy & 233.15 & 35 & .05 & .91 & .99 \\
Need for Relatedness & 13.91 & 5 & .06 & .98 & .99 \\
Satisfaction with Life & 12.19 & 9 & .07 & .97 & .99 \\
Subjective Vitality & 31.91 & 9 & & .97 \\
\hline
\end{tabular}


Table 2

Descriptive Statistics, Internal Consistency, and Correlations between Study Variables

\begin{tabular}{lccccccccc}
\hline Variable & Range & $M$ & $S D$ & $\alpha$ & 1 & 2 & 3 & 4 \\
\hline (1) Autonomy Support & $1-7$ & 5.40 & .92 & .91 & - & & & \\
(2) Need for Competence & $1-7$ & 5.55 & 1.12 & .81 & .32 & - & & \\
(3) Need for Autonomy & $1-7$ & 5.31 & 1.08 & .90 & .48 & .56 & - & \\
(4) Need for Relatedness & $1-5$ & 4.17 & .70 & .86 & .33 & .58 & .57 & - & \\
(5) Satisfaction with Life & $1-7$ & 5.73 & .96 & .78 & .30 & .43 & .43 & .49 & - \\
(6) Subjective Vitality & $1-7$ & 5.63 & 1.11 & .87 & .39 & .50 & .46 & .54 & .58 \\
\hline
\end{tabular}

Note. All correlations are significant $(p<.01)$.

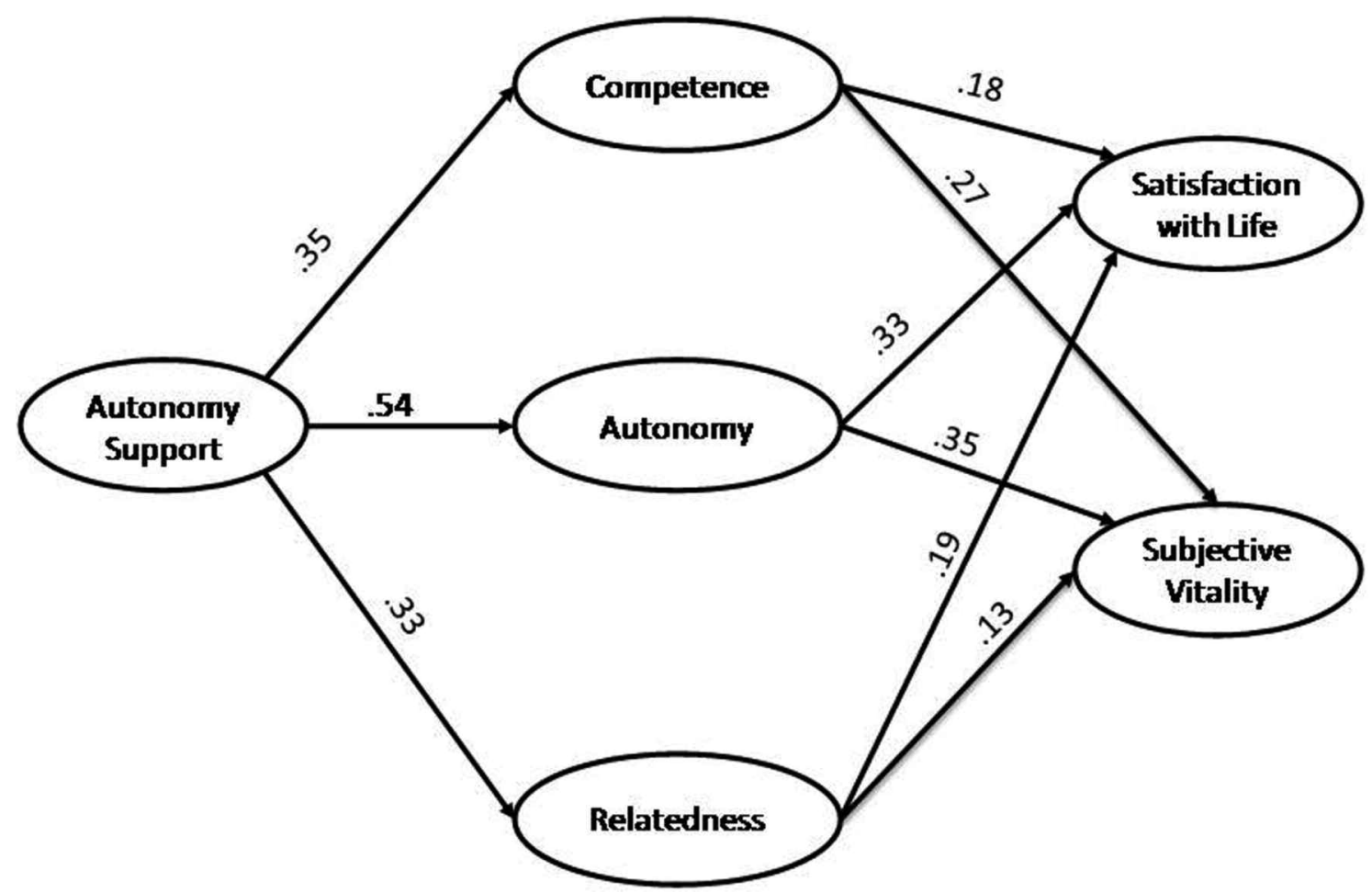

Note. All coefficients are significant $(p<.05)$. Significant correlations $(p<.01)$ between error terms (competence-autonomy $=.58$; competence-relatedness $=.59$, autonomy-relatedness $=.60$; satisfaction with life-subjective vitality $=.51)$ are not visually represented

Figure 2. Standardized Solution of the Structural Model of Antecedents and Outcomes of Basic Psychological Needs.

request). The autonomy support, perceived autonomy, and subjective vitality scales exhibited a $\chi^{2} / d f$ ratio somewhat higher than the conventional cut-off point; nevertheless, all other indices utilized were adequate.

\section{Descriptive Statistics and Pearson Correlations}

The descriptive results, internal consistency, and correlations among the study's variables appear in Table 2. The athletes exhibited high average scores on all the scales, above the response scale's nominal midpoint. Also, the instruments employed yielded high values of internal consistency ( $\alpha$ coefficients between .78 and .91). Perceived coach autonomy support was found to be positively, significantly linked to competence, autonomy, and relatedness need satisfaction, as well as the indicators of well-being (satisfaction with life and subjective vitality). The three psychological needs were positively related to one another, as well as with satisfaction with life and subjective vitality

\section{Structural Equations Analyses}

In order to assess the hypothesized model (see Figure 1), the program AMOS version 7.0 was used (Arbuckle, 2006) in addition to the same fit indices mentioned above in the Analyses of Instruments sub-section and Hoelter's 


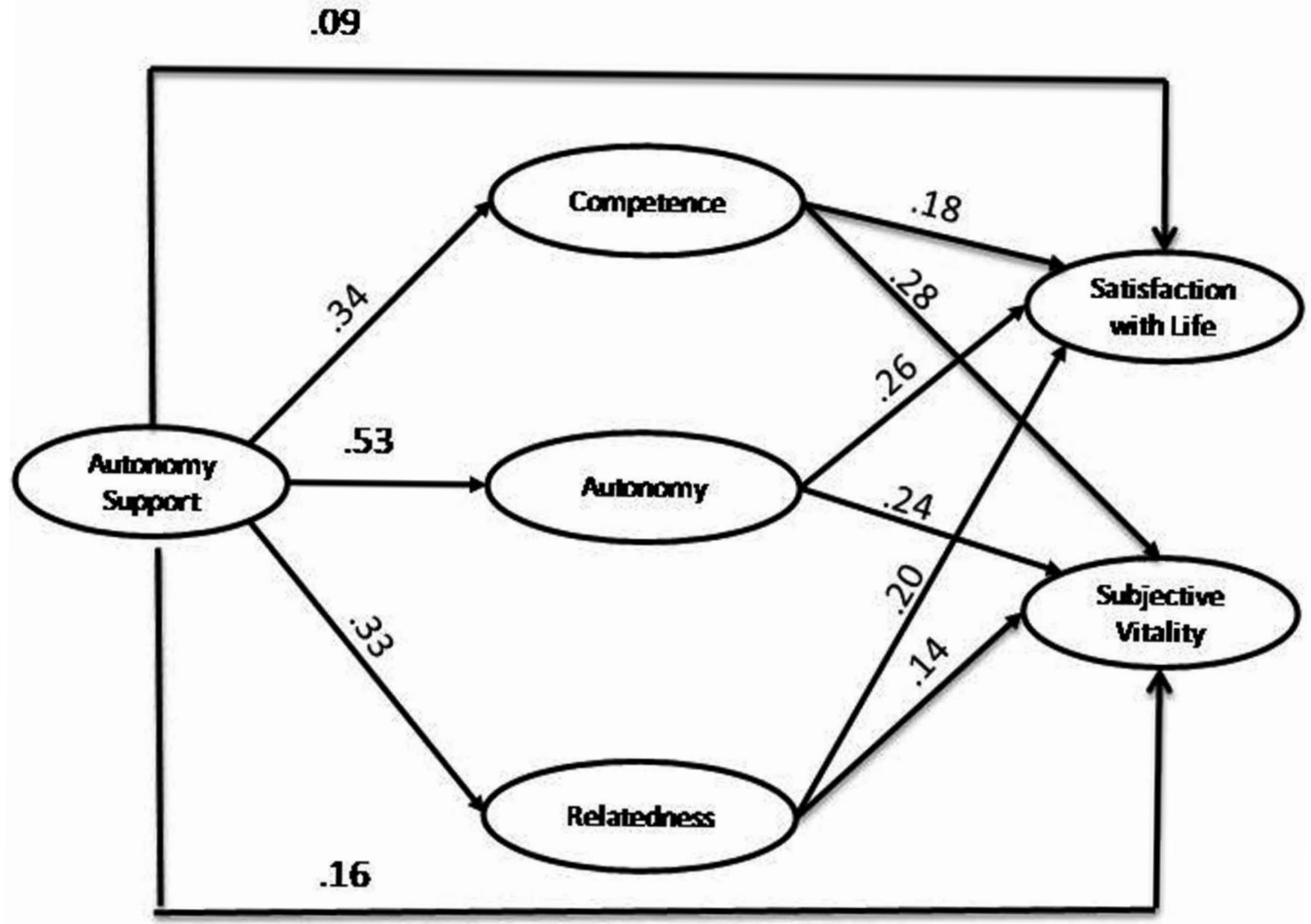

Note. All coefficients are significant $(p<.05)$.Significant correlations $(p<.01)$ between error terms (competence-autonomy $=.59$; competence-relatedness $=.59$, autonomy-relatedness $=.61$; satisfaction with life-subjective vitality $=.50)$ are not visually represented

Figure 3. Standardized Solution of the Modified Structural Model of Antecedents and Outcomes of Basic Psychological Needs.

critical N statistic (Hoelter, 1983). A Hoelter's critical N over 200 indicates satisfactory fit.

The first step was to analyze the data in terms of normal distribution, characteristics of asymmetry and kurtosis, and Mardia's coefficient of multivariate kurtosis, which is required for correct estimation (Mardia, 1974). Mardia's coefficient was found to be 103.6, indicating non-normal multivariate distribution of the data, so in order to reflect the data's robustness, we went on to apply the "bootstrap" method. Some authors (Cuttance, 1987; Muthen \& Kaplan, 1985) have verified that robust measures, which are generally employed for non-normal, multivariate distributions, exhibit substantial differences in indicators of goodness of fit in maximum likelihood estimation whenever asymmetry and kurtosis fall outside the -2 to 2 range. The range of asymmetry and kurtosis for the model's 44 items did not fall outside the -2 to 2 range, except for one item on the perceived competence scale (C4) and two from the satisfaction with life questionnaire (S3 and S4).

The model was found to have adequate goodness of fit indices: $\chi^{2}(864)=2,337.36, \chi^{2} / d f=2.70, \mathrm{CFI}=.90$, NNFI $=.90, \mathrm{RMSEA}=.05, \mathrm{~N}$ Hoelter $=276$. Figure 2 displays the standardized solution for the structural model. The results convey that perceived coach autonomy support positively predicts autonomy, competence, and relatedness need satisfaction. Additionally, satisfying the three basic psychological needs positively predicts satisfaction with life and subjective vitality. Finally, a positive, significant $(p<$ $.01)$ relationship was discovered between the error terms of competence and autonomy needs $(r=.58)$, competence and relatedness needs $(r=.59)$, autonomy and relatedness needs $(r=.60)$, and satisfaction with life and subjective vitality $(r=.51)$.

\section{The Mediation of Basic Psychological Needs}

Analysis of basic psychological needs' mediation was completed in accordance with Holmbeck's (1997) recommendations. The first step was to assess autonomy support's capacity to predict well-being, the latter being measured by satisfaction with life and vitality. The model reflected adequate fit indices: $\chi^{2}(255)=701.20, \chi^{2} / d f=2.75$, $\mathrm{CFI}=.94$, NNFI $=.94$, RMSEA $=.05$, N Hoelter $=296$. The correlations between autonomy support and the well-being variables (satisfaction with life and subjective vitality) were significant $(\beta=.36, p<.01$; and $\beta=.43, p<.01$ respectively). 
The second step in testing basic psychological needs' mediation was to establish the constrained model's fit (whose parameters appear in Figure 2). The proposed structural model yielded adequate fit indices (mentioned above). Therefore, the model meets the conditions for mediation, with significant associations between autonomy support and the mediating variables (basic psychological needs), and between the mediating variables and the variables satisfaction with life and subjective vitality.

The third step was to examine an unconstrained model, adding to the constrained model a direct relationship between autonomy support and the well-being variables (satisfaction with life and subjective vitality). The fit indices of the unconstrained model proved satisfactory: $\chi^{2}(862)=$ $2,323.74, \chi^{2} / d f=2.70, \mathrm{NNFI}=.90, \mathrm{RMSEA}=.05, \mathrm{~N}$ Hoelter $=277$. It is worth mentioning that for this model, the direct relation between autonomy support and life satisfaction $(\beta=.09, p<.05)$ and between autonomy support and vitality $(\beta=.16, p<.01)$ were found to be significant, though coefficients decreased (from $\beta=.36$ down to $\beta=.09$ for the first relationship and $\beta=.43$ down to $\beta=.16$ in the second). Thus, in both cases, a partial mediation occurred.

The final step in determining mediation was to analyze the $\chi^{2}$ difference test in the constrained (hypothesized model) and unconstrained models. The results expose differences between the two proposed models $\left(\Delta \chi^{2}{ }_{(2)}=13.62, p<.001\right)$. This indicates the direct relations between autonomy support and the two indicators of well-being significantly improved the indirect model, in which correlations were restricted, in terms of goodness of fit, leading us to refute the hypothesis of total mediation and to confirm partial mediation. Figure 3 presents the standardized solution obtained for the modified structural model.

\section{Discussion and Conclusions}

The present study was designed to test the basic psychological needs mini-theory (BNT; Ryan \& Deci, 2002) within broader Self-determination Theory (SDT; Deci \& Ryan, 2000) in Mexican athletes. The principal aim was to test the BNT sequence regarding the hypothesized relationship between perceptions of coach autonomy support, basic need satisfaction, and indices of well-being. The results offer empirical support for the BNT sequence in the context of Mexican athletes.

Specifically, in confirmation of our first hypothesis and similar to the findings of prior research (e.g. Adie et al., 2008), the results reveal that athletes' perceived coach autonomy support was positively related with satisfaction of the basic psychological needs. In support of the theoretical postulates of BNT, the data convey that when athletes perceive this type of social atmosphere, they report feeling more competent in their sports, autonomous in their actions, and a greater relatedness with significant others in their environment.

In accordance with the findings of other research studies, when the environment is perceived as autonomy supportive, its greatest predictive power was over satisfaction of the need for autonomy (Balaguer et al., 2008; Gagné et al., 2003; Reinboth et al., 2004). These results reinforce the postulates of SDT that consider autonomy to be a psychological need that to satisfy it requires the support of environmental conditions and interpersonal relationships (Deci \& Ryan 1985; Ryan \& Deci 2000, 2002). This leads us to conclude that perhaps other dimensions of social context should be taken into account, dimensions that could exert greater predictive power over satisfaction of the needs for competence and relatedness, as some prior studies have done (see Reinboth et al., 2001).

In support of the second hypothesis and the propositions of BNT, which argues that basic psychological need satisfaction is necessary for one to function optimally, the present study's results supported the findings of earlier research in the sport context (e.g. Adie et al., 2008) by reporting that when young, Mexican athletes feel competent, autonomous and supported, understood and respected by others, they also perceive themselves to have greater psychological well-being as represented by life satisfaction and subjective vitality. We observed that in the present research, satisfaction of the need for autonomy played the most relevant role by being the strongest predictor of both indicators of well-being. These results reiterate the importance that Ryan and Frederick (1997) attributed to perceived internal locus of causality in predicting a feeling of vitality. According to those authors (1997), only subjects with an internal locus of causality, meaning they feel they originate their behavior, experience their energy as their own and feel it emanating from them, ergo, they report higher levels of subjective vitality. In addition to emphasizing how important it is that athletes feel autonomous in order to perceive vitality, this study also informs us that perceived autonomy is crucial to athletes' feeling satisfied with their lives.

In short, this study provides support for each segment of the sequence proposed from the BNT perspective. However, we wish to emphasize that satisfaction of the need for autonomy seems to play the most important role in the culturally Mexican athletes studied, as both an antecedent to the well-being variables studied and a consequence of perceived coach autonomy support.

\section{The Mediation of Basic Psychological Needs}

Grounded in the postulates of BNT, this study's second objective was to test the mediational effects of the three psychological needs in the path from perceived coach autonomy support to the indicators of athletes' well-being (satisfaction with life and subjective vitality). 
Generally speaking, the results show that satisfaction of the three basic psychological needs (competence, autonomy, and relatedness) partially mediates the link from social context to the two indicators of well-being. These findings suggest that when a coach creates an autonomy supportive environment for athletes, he or she uses non-controlling language, considers athletes' perspectives and feelings, provides rationale, and offers choices. When athletes perceive this type of interaction with their coaches, they feel altogether more competent at their sports, more autonomous in their actions, and more relatedness with their peers. This in turn contributes to improved psychological well-being. In addition to lending empirical support for the postulates of BNT, these results are aligned with the findings of other authors from both the sport (e.g. Adie et al., 2008; McDonough \& Crocker, 2007) and physical education contexts (e.g. Cox \& Williams, 2008). This suggests the relation between social factors and well-being outcomes occurs both directly and through the mediation of basic psychological need satisfaction.

From a practical point of view, these results communicate that at this age, feeling competent, autonomous, and connected to one's peers is crucial to perceived well-being, and that coaches play an important role in the satisfaction of those needs.

This study provides empirical support for Basic Needs Theory (BNT; Ryan \& Deci, 2002) in a Mexican sport setting. It also reiterates the importance of the role of coach autonomy support in fomenting basic psychological need satisfaction, and therefore the psychological well-being of Mexican athletes.

Finally, we wish to point out that future research should control for certain variables not taken into account in the present study, which could be considered a research limitation. For example, this was a cross-sectional study, so we can only speak to correlations, not changes over time.

\section{References}

Adie, J. W., Duda, J. L., \& Ntoumanis, N. (2008). Autonomy support, basic need satisfaction and the optimal functioning of adult male and female sport participants: A test of basic needs theory. Motivation and Emotion, 32, 189-199. http://dx.doi.org/ 10.1007/s11031-008-9095-Z

Álvarez, M. S., Balaguer, I., Castillo, I., \& Duda, J. L. (2009). Coach autonomy support and quality of sport engagement in young soccer players. The Spanish Journal of Psychology, 12, 138-148.

Arbuckle, J. L. (2006). AMOS (Version 7.0). Chicago, IL: SmallWaters Corp.

Atienza, F. L., Pons, D., Balaguer, I., \& García-Merita, M. (2000). Psychometric properties of the satisfaction with life scale in adolescents. Psicothema, 12, 314-319.

Balaguer, I., \& Castillo, I. (2007, June). Relationship of coachprovided autonomy support to need satisfaction and well-being in young elite female tennis players. Paper presented at the 2007 Annual Meeting of the International Society for Behavioral Nutrition and Physical Activity. Oslo, Norway.

Balaguer, I., Castillo, I., \& Duda, J. L. (2008). Apoyo a la autonomía, satisfacción de las necesidades, motivación y bienestar en deportistas de competición: Un análisis de la teoría de la autodeterminación [Autonomy support, needs satisfaction, motivation, and well-being in competitive athletes: A test of Self-determination Theory]. Revista de Psicología del Deporte, 17, 123-139.

Balaguer, I., Castillo, I., Duda, J. L., \& Tomás, I. (2009). Análisis de las propiedades psicométricas de la versión española del cuestionario de clima en el deporte [Analysis of the psychometric properties of the Spanish version of the Sport Climate Questionnaire]. Revista de Psicología del Deporte, 18, 73-83.

Balaguer, I., Castillo, I., García-Merita, M., \& Mars, L. (2005, July). Implications of structured extracurricular activities on adolescent's well being and risk behaviors: motivational mechanisms. Paper presented at the 9th European Congress of Psychology. Granada. Spain.

Browne, M. W., \& Cudeck, R. (1993). Alternative ways of assessing model fit. In K. A. Bollen, \& J. S. Long (Eds.), Testing structural equation models (pp. 136-162). Newsbury Park, CA: Sage.

Cox, A., \& Williams, L. (2008). The roles of perceived teacher support, motivational climate, and psychological need satisfaction in students' physical education motivation. Journal of Sport \& Exercise Psychology, 30, 222-239.

Cronbach, L. J. (1951). Coefficient alpha and the internal structure of tests. Psychometrika, 16, 297-334. http://dx.doi.org/10.1007/ BF02310555

Cuttance, P. (1987). Issues and problems in the application of structural equation models. In P. Cuttance \& R. Ecob (Eds.), Structural Modeling by Example (pp. 241-279). New York, NY: Cambridge University Press. http://dx.doi.org/10.1017/ CBO9780511601118.014

Deci, E. L., \& Ryan, R. M. (1985). Intrinsic motivation and selfdetermination in human behavior. New York, NY: Plenum

Deci, E. L., \& Ryan, R. M. (2000). The "what" and "why" of goal pursuits: Human needs and the self-determination of behavior. Psychological Inquiry, 11, 227-268. http://dx.doi.org/ 10.1207/S15327965PLI1104_01

Deci, E. L., \& Ryan, R. M. (n.d.). Self Determination Theory $S D T$. University of Rochester, Rochester, NY. Retrieved from http://www.psych.rochester.edu/SDT/

Deci, E. L., \& Ryan, R. M. (n.d.). Sport Climate Questionnaire. University of Rochester, Rochester, NY. Retrieved from http://www.selfdeterminationtheory.org/questionnaires/10questionnaires/84

Diener, E., Emmons, R. A., Larsen, R. J., \& Griffin, S. (1985). The Satisfaction With Life Scale. Journal of Personality Assessment, 49, 71-75. http://dx.doi.org/10.1207/s15327752jpa4901_13

Duda, J. L., \& Hayashi, C. T. (1998). Measurement issues in crosscultural research within sport and exercise psychology. In J. L. Duda (Ed.), Advances in sport and exercise psychology 
measurement (pp. 471-483). Morgantown, WV: Fitness Information Technology, Inc.

Edmunds, J., Ntoumanis, N., \& Duda, J. L. (2007). Adherence and well-being in overweight and obese patients referred to an exercise on prescription scheme: A self-determination theory perspective. Psychology of Sport \& Exercise, 8, 722-740. http://dx.doi.org/10.1016/j.psychsport.2006.07.006

Gagne, M., Ryan, R. M., \& Bargmann, K. (2003). Autonomy support and need satisfaction in the motivation and well-being of gymnasts. Journal of Applied Sport Psychology, 15, 372390. http://dx.doi.org/10.1080/714044203

Fierro, D., \& Moreno, A. (2007). Emerging adulthood in Mexican and Spanish youth - Theories and realities. Journal of Adolescent Research, 22, 476-503. http://dx.doi.org/10.1177/074355840 7305774

Hoelter, J. W. (1983). The analysis of covariance structures: Goodness of fit indices. Sociological Methods and Research, 11, 325-344. http://dx.doi.org/10.1177/0049124183011003003

Holmbeck, G. N. (1997). Toward terminological, conceptual, and statistical clarity in the study of mediators and moderators: Examples from the child-clinical and pediatric psychology literatures. Journal of Consulting and Clinical Psychology, 65, 599-610. http://dx.doi.org/10.1037//0022-006X.65.4.599

Hu, L.-T., \& Bentler, P. (1995). Evaluating model fit. In R. H. Hoyle (Ed.), Structural equation modeling. Concepts, issues, and applications (pp. 76-99). London, England: Sage.

Hu, L., \& Bentler, P. M. (1999). Cut-off criteria for fit indexes in covariance structure analysis: Conventional criteria versus new alternatives. Structural Equation Modeling, 6, 1-55. http://dx.doi.org/10.1080/10705519909540118

López-Walle, J., Tomás, I., Castillo, I., Tristán, J., \& Balaguer, I. (2011). Invarianza factorial del TEOSQ en jóvenes deportistas mexicanos y españoles [Cross-cultural validation of the TEOSQ in Mexican and Spanish junior athletes]. Revista Mexicana de Psicología, 28, 53-61.

Mardia, K. V. (1974). Applications of some measures of multivariate skewness and kurtosis in testing normality and robustness studies. Sankhya, Series B, 36, 115-128.

McAuley, E., Duncan, T., \& Tammen, V. V. (1989). Psychometric properties of the intrinsic motivation inventory in a competitive sport setting-a confirmatory factor-analysis. Research Quarterly for Exercise \& Sport, 60, 48-58.

McDonough, M. H., \& Crocker, P. R. E. (2007). Testing selfdetermined motivation as a mediator of the relationship between psychological needs and affective and behavioral outcomes. Journal of Sport \& Exercise Psychology, 29, 645-663.

Muñiz, J. (1996). Psicometría [Psychometrics]. Madrid, Spain: Universitas, S.A.

Muthen, B., \& Kaplan, D. (1985). A comparison of some methodologies for the factor analysis of non-normal Likert variables. British Journal of Mathematical and Statistical Psychology, 38, 171-189. http://dx.doi.org/10.1111/j.20448317.1985.tb00832.x
Pavot, W., Diener, E., Colvin, C. R., \& Sandvik, E. (1991). Further validation of the Satisfaction With Life Scale: Evidence for the cross-method convergence of well-being. Journal of Personality Assessment, 57, 149-161. http://dx.doi.org/10.1207/ s15327752jpa5701_17

Pérez-Gil, J. A., Moscoso, S. C., \& Rodríguez, R. M. (2000). Construct validity: The rise of factor analysis. Psicothema, 12, 442-446.

Reinboth, M., \& Duda, J. L. (2006). Perceived motivational climate, need satisfaction and indices of well-being in team sports: A longitudinal perspective. Psychology of Sport and Exercise, 7, 269-286. http://dx.doi.org/10.1016/j.psychsport. 2005.06.002

Reinboth, M., Duda, J. L., \& Ntoumanis, N. (2004). Dimensions of coaching behavior, need satisfaction, and the psychological and physical welfare of young athletes. Motivation and Emotion, 28, 297-313. http://dx.doi.org/10.1023/B:MOEM. 0000040156.81924.b8

Richer, S., \& Vallerand, R. J. (1998). Construction and validation of the Perceived Relatedness Scale. Revue Européene de Psychologie Appliquée, 48, 129-137.

Ryan, R. M., \& Deci, E. L. (2000). Self-determination theory and the facilitation of intrinsic motivation, social development, and well-being. American Psychologist, 55, 68-78. http://dx.doi.org/ 10.1037//0003-066X.55.1.68

Ryan, R. M., \& Deci, E. L. (2001). On happiness and human potentials: A review of research on hedonic and eudaimonic well-being. Annual Review of Psychology, 52, 141-66. http://dx. doi.org/10.1146/annurev.psych.52.1.141

Ryan, R. M., \& Deci, E. L. (2002). An overview of selfdetermination theory: An organismic dialectical perspective. In E. L. Deci, \& R. Ryan, (Eds.), Handbook of Selfdetermination Research (pp. 3-33). Rochester, NY: University of Rochester Press.

Ryan, R. M., \& Deci, E. L. (2007). Active human nature: Selfdetermination theory and the promotion and maintenance of sport, exercise, and health. In M. S. Hagger, \& N. L. Chatzisarantis (Eds.), Intrinsic motivation and self-determination in exercise and sport (pp. 1-19). Champaign, IL: Human Kinetics.

Ryan, R. M., \& Frederick, C. (1997). On energy, personality, and health: Subjective vitality as a dynamic reflection of wellbeing. Journal of Personality, 65, 529-565. http://dx.doi.org/10. 1111/j.1467-6494.1997.tb00326.x

Williams, G. C., Grow, V. M., Freedman, Z., Ryan, R. M., \& Deci, E. L. (1996). Motivational predictors of weight loss and weightloss maintenance. Journal of Personality and Social Psychology, 70, 115-126. http://dx.doi.org/10.1037//0022-3514.70.1.115

Received February 24, 2011

Revision received August 19, 2011 Accepted September 15, 2011 